\title{
Policy Feedback and Economic Risk: The Influence of Privatization on Social Policy Preferences Online Appendix
}

\author{
Ling Zhu \\ Department of Political Science \\ 436 Philip G. Hoffman Hall \\ University of Houston \\ Houston, TX 77204-3011 \\ lzhu4@central.uh.edu \\ and \\ Christine S. Lipsmeyer \\ Department of Political Science \\ TAMUS 4348 \\ Texas A\&M University \\ College Station, TX 77843-4348 \\ lipsmeyer@tamu.edu
}


In this document, we present additional details for: robustness checks for possible reverse causality, the measurement design of our healthcare privatization index, results using an alternative dependent variable, results using an alternative model specification, and a figure showing the effect of privatization contingent on risk (the other half of the interactive relationship) (?).

\section{Potential Reverse Causality}

We argue that the direct effect of privatized healthcare systems leads to low-levels of support for more government healthcare spending. Possibly, negative attitudes toward government spending could foster private healthcare systems. To rule out potential reverse causality, we conduct two robustness checks. First, we check the bivariate association between country-level aggregated healthcare preferences and the privatization measure (see Figure 6). We do not find a strong negative association between the level of support for more government healthcare spending and the level of privatization. In our sample, we have country cases, such as South Korea, where a high level of privatization coexists with a high level of support for more government healthcare spending. Similarly, in countries such as Australia, Norway, and Finland, over $80 \%$ of the respondents support increasing government healthcare spending, yet these countries score relatively high on the privatization index. We also observe country cases, such as Netherlands and Canada, where the support for more government healthcare spending is relatively low, but the national healthcare systems are more publicly oriented.

Second, we run a regression model based on the country-level latent means and check if aggregated healthcare preferences significantly predict the privatization variable (see Table 7) (?). The status quo level of public healthcare spending (as a percentage of national GDP) has a significant and negative relationship with the privatization variable. However, we do not find evidence for reverse causality: that aggregated healthcare preferences significantly predict the level of privatization. The coefficient of the variable for aggregated healthcare preferences is near zero $(b=-0.037)$ and statistically insignificant.

[Figure 6 About Here]

[Table 7 About Here]

\section{Applying the Item Response Theory to Scaling Multiple Institutional Arrange- ments}

As mentioned in the paper, we apply the Item Response Theory (IRT) ${ }^{1}$ to scaling multiple institutional indicators that determine the level of privatization of healthcare responsibil-

\footnotetext{
${ }^{1} ?$
} 
ities. Researchers commonly use IRT models as tools to advance quantitative measures of latent constructs that either are not directly observable (e.g., intellectual ability) ?, or take compound layers of meanings (e.g., democracy) ?. This latent variable measurement strategy has two steps. First, we collect multiple observable indicators for the underlying latent trait, and second, we apply a specific IRT model to infer statistically the latent dimension based on the bundle of observed indicators.

In our analysis, we examine multiple institutional arrangements that capture the level of healthcare privatization. We collect information on nine institutional indicators to capture the Structure, Coverage, and Financing aspects of healthcare privatization in 29 OECD countries (the total number of countries in the OECD Health Survey). ${ }^{2}$ We code all of these institutional variables as ordinal variables. As such, the country-institution data matrix permits a comprehensive assessment on: (1) within each country, how privatization is institutionalized; and (2) along each institutional indicator, what is the specific across-country variation in privatization.

Table 1 provides details for each institutional indicator and its corresponding coding. From the OECD expert survey, the codings for the institutional indicators are as follows:

- Structure measures the institutional set-up of basic primary healthcare coverage. $1=$ government health service (including national and local health service) systems; $2=$ social insurance systems with common insurance schemes; and 3= market-oriented social insurance systems with multiple insurers.

- Coverage measures the scope of primary healthcare coverage. $1=100 \%$ automatic coverage; $2=$ compulsory or automatic-compulsory coverage; $3=$ a substantial proportion of the population is covered by voluntary coverage.

- Acute Through Pharm measure the public-private division in financing (1) acute inpatient care, (2) out-patient physician visits, (3) out-patient specialist visits, (4)testing, (5) imaging, and (6) pharmaceuticals. The OECD codes these values based on the share of typical costs covered by basic primary health coverage: $1=100 \%$; $2=76-99 \%$; $3=51-75 \%$; and $4=$ less than $50 \%$. A greater value means more private responsibility.

- Prtotal2 measures the percentage of total private healthcare spending (i.e., private insurance and out-of-pocket combined) as a share of total health spending in 2005. Prtotal1 converts Prtotal 2 into a 1-to-4 ordered scale based on quartiles.

\section{[Table 1 About Here]}

One statistical challenge we encounter is that Prtotal2 is coded as a continuous variable, while all the others are categorical variables. There are three possible ways to scale

\footnotetext{
${ }^{2}$ Limited availability for other variables in our model limits the sample in the paper to 19 countries.
} 
these institutional indicators into a combined index: (1) using factor analysis to estimate a combined index, ignoring the ordinal nature of most institutional indicators; (2) rescaling the continuous variable, Prtotal 2 into a 1-to- 4 ordinal scale based on quartiles (i.e., to use Prtotal1) and then estimating an IRT index; and (3) using Bayesian factor analysis for mixed data recommended by (?).

We estimate three different privatization indexes and then compare their measurement reliabilities. We compute the first privatization index using factor analysis. For the second privatization index, we apply a one parameter graded-response model (GRM) to Polytomous institutional indicators on one measurement scale ${ }^{3}$ and implement the statistical computation using the R package $\mathrm{ltm}$ ?. The IRT measurement model is expressed formally by equation (1) (?,13). Specifically, the latent level of privatization $\theta_{i k}$ in country $i$ and across $k$ institutional indicators is conceptualized as a function of the difference in the marginal probabilities of observing a lower level of privatization $(c-1)$ and observing a higher level of privatization $(c)$. The GRM model utilizes an ordered-logistic likelihood function and recovers information pertaining to the latent level of privatization based on the probability distributions across all observed levels of privatization.

$$
P\left(Y_{i k}=c \mid \theta_{i, k}\right)=P\left(Y_{i k}>=c-1 \mid \theta_{i, k}\right)-P\left(Y_{i k}>c \mid \theta_{i, k}\right)
$$

This IRT approach also accounts for how the observed score associated with each item contributes to the latent privatization score. Table 2 reports the full set of item-difficulty parameters associated with each observed institutional indicator. These difficulty parameters are linked to the cut points for observed categories, indicating how each choice category of the nine institutional items is mapped onto the latent privatization scale. Given that we have a small-N information matrix (29 countries $\times 9$ institutional indicators), we need to consider the uncertainty of parameter estimations in our measurement strategy. Following the existing literature, we use the empirical Bayes method to calibrate a mean privatization score for each country after fitting the IRT model (??). The empirical Bayes scoring method uses Monte Carlo simulations to explicitly acknowledge the uncertainty about true underlying parameter values associated with each institutional indicator. We plot the full set of mean privatization scores with their $95 \%$ credible intervals in Figure 1. The third privatization index is estimated based on Bayesian factor analysis, using the MCMCpack package in $R($ ?).

[Table 2 About Here]

[Figure 1 About Here]

For a few reasons, the IRT index performs the best. First, as suggested by the comparative healthcare institutions literature, specific healthcare institution indicators do not

${ }^{3} ?$. 
cluster on one single dimension. When using factor analysis to extract the latent privatization index from multi-dimension clusters, the index does not recover data information efficiently. While the three privatization indexes are correlated positively, with high correlation scores, the northwest tile in Figure 2 shows that the two factor indices (Factor Index and Bayesian Factor Index) are not distributed as normal distributions. They show some bimodal patterns, which is problematic.

\section{[Figure 2 About Here]}

Second, the IRT method has an advantage over factor analysis in capturing variations across institutional items and across countries. As Figure 3 demonstrates, each institutional indicator contributes a distribution of probability scores corresponding to different observed levels of privatization. We then combine distributional information for nine different institutional indicators into one measurement scale. This estimated IRT measurement scale recovers nearly $90 \%$ of the total information in the data matrix with a slightly skewed distribution toward the high level of privatization (see the first subfigure in Figure 3).

\section{[Figure 3 About Here]}

Third, the IRT index outperforms the Bayesian factor index in terms of differentiating countries that have more public-oriented health care systems. The Bayesian factor index does not perform well, because these scores are predicted based on the first factor out of the four significant factors. The first factor is more or less driven by the cluster of financing indicators and under-estimates other indicators such as structure and coverage.

As both Table 1 and Figure 1 show, the IRT measure of privatization permits a calibration of nuanced institutional differences across different countries. It captures different levels of privatization within each structural or coverage cluster. For example, levels of privatization differ across national health service systems because of the scope of financial responsibilities for actual healthcare services (e.g., the comparison between UK, Canada, and Denmark). As for countries with social insurance systems, a privatization score is not necessarily high if most of the health services are financed through the public domain (e.g. Belgium and Germany). Similarly, if a country's system provides almost universal coverage of primary health care, but only uses the public budget to fund a limited number of services, the privatization score can be relatively high (e.g. Ireland or New Zealand). The IRT measure reflects well the theoretical idea that in the domain of healthcare, institutional set-ups for privatization take complex forms and are not determined by one simple linear measure based on more or less government spending. 


\section{Alternative Dependent Variable: Government Responsibility for Providing Care to the Sick}

Although in the literature (???), spending preferences are the dominant way of measuring individuals' social policy preferences, one may also have specific ideas about the role of government in providing care for the sick. In this Appendix, we adopt an alternative dependent variable that measures healthcare preferences through government responsibility for sickness care. We show the model results for this alternative dependent variable in Table 3. Similar to the model reported in the text, we code this variable as dichotomous with 1 equal to "strongly agree that the government should increase responsibility to provide care to the sick" and 0 otherwise. Figure 4 corresponds to the interactive relationship between risk and privatization.

\section{[Table 3 About Here]}

[Figure 4 About Here]

A comparison of Figure 2(b) from the paper with Figure 4 using the alternative dependent variable shown here emphasizes the robustness of our findings pertaining to the Privatization variable. Both figures find consistent evidence that healthcare privatization substantially reduces support for more government healthcare spending, as well as for more government responsibility for the care of the sick.

\section{Robustness Checks with Alternative Model Specification}

\subsection{Coding the ISSP Spending Variable as 3-Choice Categories}

In the original ISSP 2006 Role of Government dataset, the variable for preferences toward increasing government spending in healthcare originally has 5 categories: (government should spend) "much more," "more," "about the same," "less," and "much less." In our analysis, we recoded choices 1 and 2 (spending much more and more) into 1 and combine the status-quo choice with the other two choices favoring less spending into 0 . In order to ensure that this recoding does not substantively overlook the cross-country variation in support for the status quo level of government spending, we reestimate the model, coding the ISSP survey item into a three-choice ordinal variable. In this robustness analysis, we code "much more" and "more" as 3, "about the same" as 2, "less" and "much less" as 1. Table 4 reports results based on a one-level ordered logit specification, and Figure 5 plots the interactive relationship between risk and privatization. As we see in Table 4, recoding the ISSP spending variable as a three-choice ordinal variable does not substantively change the key findings reported in the paper. Comparing the interaction figure in the text and Figure 5, we observe almost identical interaction patterns in the two figures. 
[Table 4 About Here]

[Figure 5 About Here]

\subsection{Considering Cross-Country Heterogeneity}

In the paper, we follow Franzese's recommendation (?). and use the one-step micro-macro interaction strategy for estimating the empirical models rather than a more complex HLM shrinkage estimator. We point to two reasons: 1) we have a limited number of higher-level cases (9 occupation groups and 19 countries), so a multi-level logistic model with hierarchical shrinkage estimators does not substantially improve our original model specification (????); and 2) estimation reliability becomes questionable with such a small number of countries.

Using cross-country public opinion data to test the effect of macro-level policy institutions on micro-level preferences, it is also important to consider the possibility that country-level heterogeneity (e.g., different cultures, historical backgrounds, or some other unobserved political factors) may affect both health care privatization and economic protection. In Table 5, we show the results of an alternative multi-level model specification with country-level random-effects that address cross-country heterogeneity. We estimate the model using the Stata 12 package, GLLAMM. In comparing the GLLAMM model results with those reported in the paper, we find similar patterns for the relationships. Not surprisingly, given our limited sample size of 19 countries, the results in Table 5 show how the multi-level estimation "shrinks" the effect of risk and privatization at the second level.

\section{[Table 5 About Here]}

Another common practice to handle cross-country heterogeneity is to cluster standard errors by country. In Table 6, we show the results of the one-step micro-macro interaction model (i.e., the same specification as the model reported in the paper) with standard errors clustered by country. This does not substantially alter the model results regarding the effect of policy institutions (Privatization). After clustering standard errors by country, however, the interaction term between risk and privatization becomes statistically insignificant $(z=-1.45)$, due to our limited sample size of 19 countries.

[Table 6 About Here]

\section{The Marginal Effects of Privatization on Healthcare Preferences}

A multiplicative interaction between two independent variables has a symmetrical relationship that specifies that the effect of each variable is contingent on the other(?). In the 
paper, our theoretical interest was in the effect of risk contingent on privatization. To complete the relationship, here, we also show how the effect of privatization is contingent on risk. The graphs in Figure 7 illustrate: 1) the marginal effect of privatization as risk varies, and 2) the predicted probability of supporting more government healthcare spending for the full range of the privatization variable when setting risk at its low- and high-levels.

[Figure 7 About Here] 


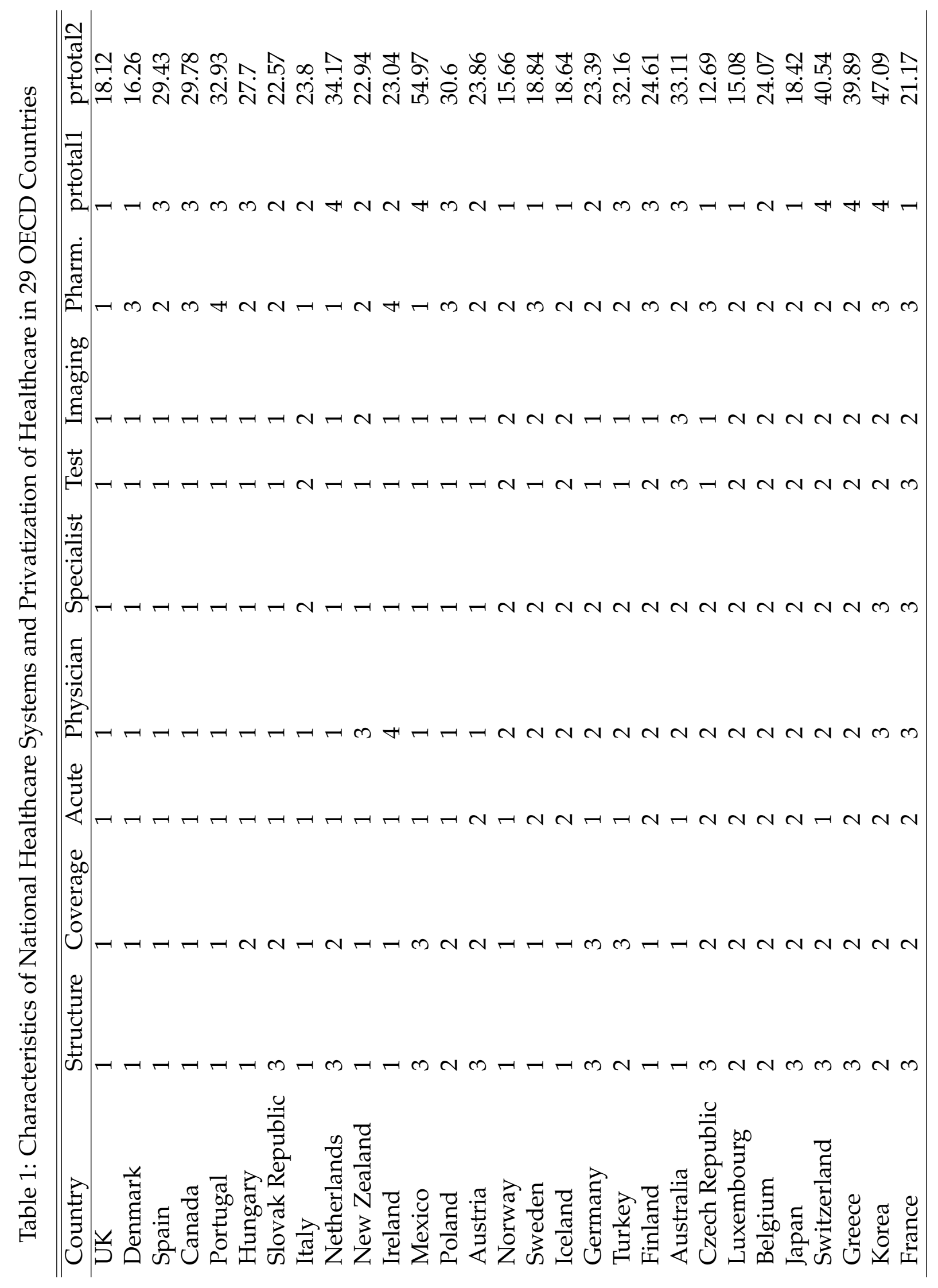


Table 2: Estimated Difficulty Parameters for Each Privatization Item

\begin{tabular}{llll}
\hline \hline Privatization Item & Cut Point 1 & Cut Point 2 & Cut Point 3 \\
\hline Structure & -0.012 & 0.855 & - \\
Coverage & -0.182 & 2.616 & - \\
Acute & 0.604 & 0.974 & - \\
Physician & -0.378 & 2.355 & 4.001 \\
Specialist & -0.296 & 3.146 & - \\
Test & 0.442 & 3.143 & - \\
Imaging & 0.273 & 3.921 & - \\
Pharmaceuticals & -2.006 & 0.900 & 3.026 \\
Private Health Spending & -0.948 & 0.109 & 1.659 \\
\hline
\end{tabular}


Table 3: Effects of Risk and Privatization of Healthcare Responsibility on Support for Increasing Government Responsibility of Providing Healthcare for the Sick

\begin{tabular}{|c|c|c|}
\hline Variable & Coefficient & (Robust SE) \\
\hline \multicolumn{3}{|c|}{ DV=Popular Demand for Government Responsibility in Healthcare } \\
\hline Risk & -0.0063 & $(0.0058)$ \\
\hline Privatization & $-0.6584^{*}$ & $(0.0326)$ \\
\hline Risk $\times$ Privatization & -0.0134 & $(0.0126)$ \\
\hline Income & $-0 . \overline{0} 05 \overline{1}^{*}$ & $(\overline{0} . \overline{0} 09)$ \\
\hline Skill & 0.0396 & $(0.0337)$ \\
\hline Income $\times$ Skill & $0.0026 \dagger$ & $(0.0013)$ \\
\hline Income $\times$ Risk & $-0.0003 \dagger$ & $(0.0002)$ \\
\hline Income $\times$ Privatization & 0.0011 & $(0.0009)$ \\
\hline Age & $0.0502^{*}$ & $(0.0175)$ \\
\hline Not in Labor Force & $0.1721^{*}$ & $(0.0486)$ \\
\hline Male & $-0.1405^{*}$ & $(0.0416)$ \\
\hline Married & 0.0108 & $(0.0451)$ \\
\hline Education & 0.0068 & $(0.0166)$ \\
\hline L-R Party Support & $-0.1706^{*}$ & $(0.0192)$ \\
\hline Union Member & $0.4412^{*}$ & $(0.0500)$ \\
\hline Public Health Spending & $0.0018^{*}$ & $(0.0185)$ \\
\hline Intercept & $0.6578^{*}$ & $(0.0471)$ \\
\hline $\bar{N}^{--n^{\prime}-}$ & $\overline{1} \overline{3} 2 \overline{4} \overline{8}^{-}$ & \\
\hline Pseudo $R^{2}$ & 0.0752 & \\
\hline
\end{tabular}

Significance level $: \dagger: \mathrm{p}<.10, *: \mathrm{p}<.05$, two-tailed test. 
Table 4: Effects of Risk and Privatization of Healthcare Responsibility on Support for Government Spending in Healthcare

\begin{tabular}{|c|c|c|}
\hline Variable & Coefficient & (Robust SE) \\
\hline \multicolumn{3}{|c|}{ DV: Support for More Government Spending in Healthcare } \\
\hline Risk & 0.0077 & $(0.0073)$ \\
\hline Privatization & $-0.5547^{*}$ & $(0.0408)$ \\
\hline Risk $\times$ privatization & $-0.0549^{*}$ & $(0.0161)$ \\
\hline Income & $-0.00 \overline{5} 8^{*}$ & $(0.0010)$ \\
\hline Skill & $0.0870^{*}$ & $(0.0422)$ \\
\hline Income $\times$ Skill & $0.0041^{*}$ & $(0.0016)$ \\
\hline Income $\times$ Risk & -0.0001 & $(0.0002)$ \\
\hline Income $\times$ Privatization & $0.0020^{\dagger}$ & $(0.0011)$ \\
\hline Age & $-0.0058^{*}$ & $(0.0200)$ \\
\hline Not in Labor Force & 0.0278 & $(0.0056)$ \\
\hline Male & $-0.3520^{*}$ & $(0.0473)$ \\
\hline Married & $0.2337^{*}$ & $(0.0515)$ \\
\hline Education & $-0.0482^{*}$ & $(0.0190)$ \\
\hline L-R Party Support & $-0.1968^{*}$ & $(0.0221)$ \\
\hline Union Member & $0.3262^{*}$ & $(0.0557)$ \\
\hline Public Health Spending & $-0.2979 *$ & $(0.0222)$ \\
\hline$\overline{\mathrm{C}} \overline{\mathrm{u}} \overline{\mathrm{P}}$ Point $\overline{1}-\cdots$ & $-\overline{-3 . \overline{7} 8 \overline{4} \overline{7}^{*}}$ & $(\overline{0} . \overline{0} \overline{7} \overline{8} 6)$ \\
\hline Cut Point 2 & $-1.3556^{*}$ & $(0.0539)$ \\
\hline $\mathrm{N}$ & 13233 & \\
\hline Pseudo $R^{2}$ & 0.0432 & \\
\hline
\end{tabular}

Significance levels : $\quad \dagger: 10 \% \quad *: 5 \%$, two-tailed test 
Table 5: Effects of Risk and Privatization of Healthcare Responsibility on Support for Increasing Government Spending in Healthcare (Multi-Level Specification with CountryLevel Random Effects)

\begin{tabular}{|c|c|c|}
\hline Variable & Coefficient & (Robust SE) \\
\hline \multicolumn{3}{|c|}{ DV: Support for More Government Spending in Healthcare } \\
\hline Risk & 0.0112 & $(0.0078)$ \\
\hline Privatization & $-0.5098^{*}$ & $(0.0363)$ \\
\hline Risk $\times$ Privatization & 0.0117 & $(0.0144)$ \\
\hline Income $^{-}$ & $-0.00 \overline{4} 1^{*}$ & $(0.0010)$ \\
\hline Skill & 0.0627 & $(0.0419)$ \\
\hline Income $\times$ Skill & $0.0038^{*}$ & $(0.0015)$ \\
\hline Income $\times$ Risk & -0.00005 & $(0.0003)$ \\
\hline Income $\times$ Privatization & $0.0029^{*}$ & $(0.0010$ \\
\hline Age & -0.0147 & $(0.0207)$ \\
\hline Not in Labor Force & 0.0064 & $(0.0583)$ \\
\hline Male & $-0.3543^{*}$ & $(0.0480)$ \\
\hline Married & $0.2057^{*}$ & $(0.0532)$ \\
\hline Education & $-0.0968^{*}$ & $(0.0196)$ \\
\hline L-R Party Support & $-0.2120^{*}$ & 0.0029 \\
\hline Union Member & $0.1393^{*}$ & $(0.0570)$ \\
\hline Public Health Spending & $-0.3726^{*}$ & $(0.0224)$ \\
\hline Country-Level Variance & $0.2 \overline{4} 1^{*}$ & $(\overline{0} . \overline{0} 3 \overline{1})$ \\
\hline $\mathrm{N}$ & 13233 & \\
\hline $\mathrm{N}$ of Countries & 19 & \\
\hline
\end{tabular}


Table 6: Effects of Risk and Privatization of Healthcare Responsibility on Support for Increasing Government Spending in Healthcare

\begin{tabular}{|c|c|c|}
\hline Variable & Coefficient & (Clustered SE) \\
\hline Risk & 0.0072 & $(0.0180)$ \\
\hline Privatization & $-0.5353^{*}$ & $(0.1600)$ \\
\hline Risk $\times$ Privatization & -0.0556 & $(0.0384)$ \\
\hline İncome & $-0 . \overline{0} 0 \overline{5} \overline{5}^{*}$ & $\overline{(0.0 \overline{1} \overline{1})})^{-}$ \\
\hline Skill & $0.0912^{*}$ & $(0.0379)$ \\
\hline Income $\times$ Skill & $0.0039^{*}$ & $(0.0017)$ \\
\hline Income $\times$ Risk & -0.0001 & $(0.0003)$ \\
\hline Income $\times$ Privatization & 0.0020 & $(0.0021)$ \\
\hline Age & -0.0076 & $(0.0314)$ \\
\hline Not in Labor Force & 0.0181 & $(0.0705)$ \\
\hline Male & $-0.3536^{*}$ & $(0.0794)$ \\
\hline Married & $0.2287^{*}$ & $(0.0540)$ \\
\hline Education & -0.0537 & $(0.0342)$ \\
\hline L-R Party Support & $-0.1936^{*}$ & $(0.0410)$ \\
\hline Union Member & $0.2992^{*}$ & $(0.0889)$ \\
\hline Public Health Spending & $-0.2869^{*}$ & $(0.0906)$ \\
\hline Intercept & $1.374 \overline{1}^{*}$ & $(0 . \overline{1} 84 \overline{3})$ \\
\hline $\mathrm{N}$ & 13233 & \\
\hline Pseudo $R^{2}$ & 0.0470 & \\
\hline
\end{tabular}


Table 7: Determinants of Healthcare Privatization: Regression Analysis of Country-Level Latent Means

\begin{tabular}{|c|c|c|}
\hline Variable & Coefficient & (Std. Err.) \\
\hline \% Support More Government Heathcare Spending & -0.0359 & $(0.0250)$ \\
\hline Risk & -0.0422 & $(0.1164)$ \\
\hline Income & 0.0156 & $(0.0748)$ \\
\hline Skill & 0.9271 & (3.2419) \\
\hline Education & -0.5092 & $(0.9944)$ \\
\hline L-R Party Support & 0.5407 & $(0.8546)$ \\
\hline Union & 1.2990 & $(0.8949)$ \\
\hline Health Care Spending & $-0.4376^{*}$ & $(0.1760)$ \\
\hline Intercept & $5.1772^{\dagger}$ & (2.4977) \\
\hline $\mathrm{N}$ & \multicolumn{2}{|c|}{19} \\
\hline $\mathrm{R}^{2}$ & \multicolumn{2}{|c|}{0.5148} \\
\hline $\mathrm{F}_{(8,10)}$ & \multicolumn{2}{|c|}{3.912} \\
\hline
\end{tabular}


Figure 1: Privatization of Healthcare Responsibility

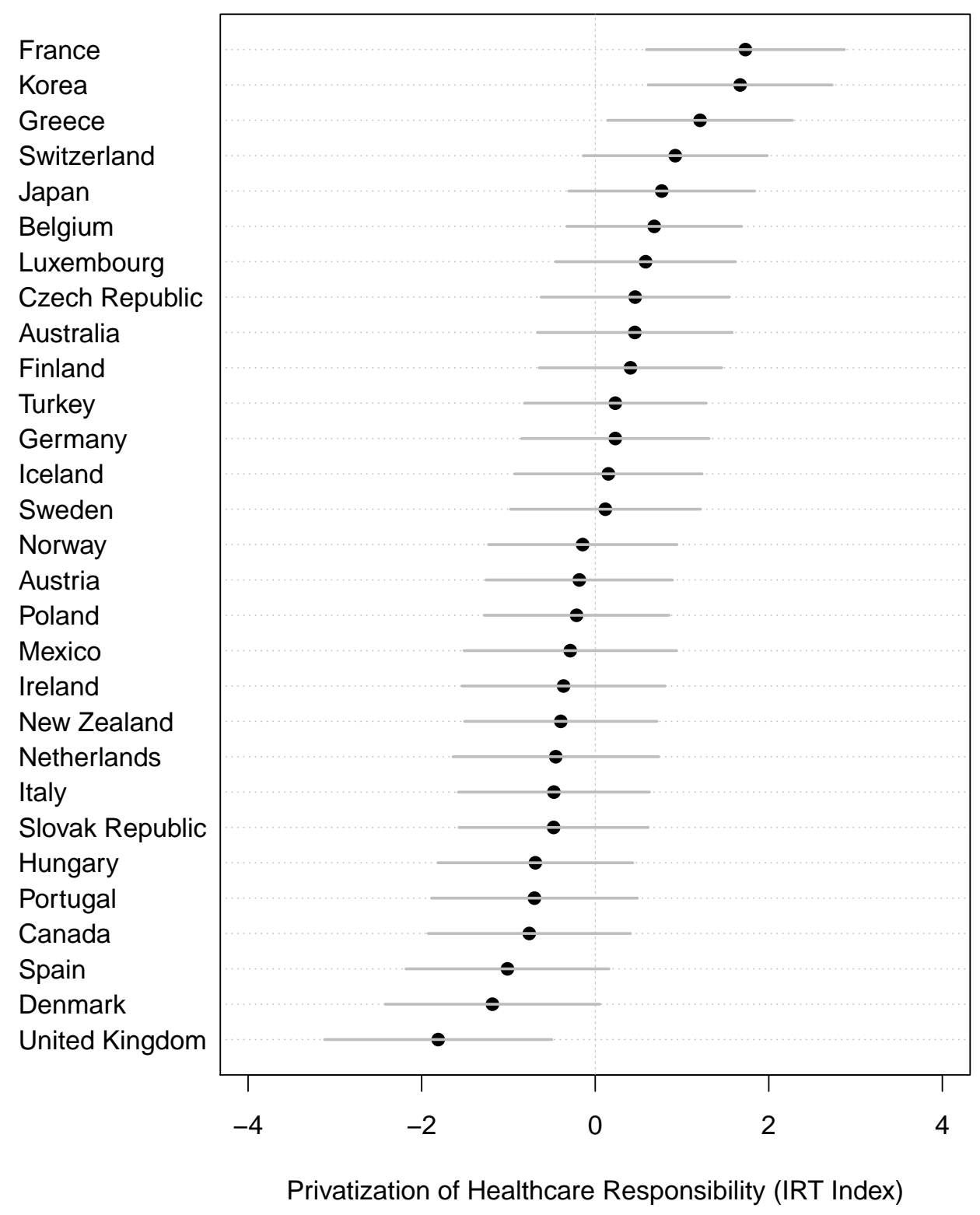


Figure 2: Compare Three Privatization Indexes: Factor Index, IRT Index, and Bayesian Factor Index
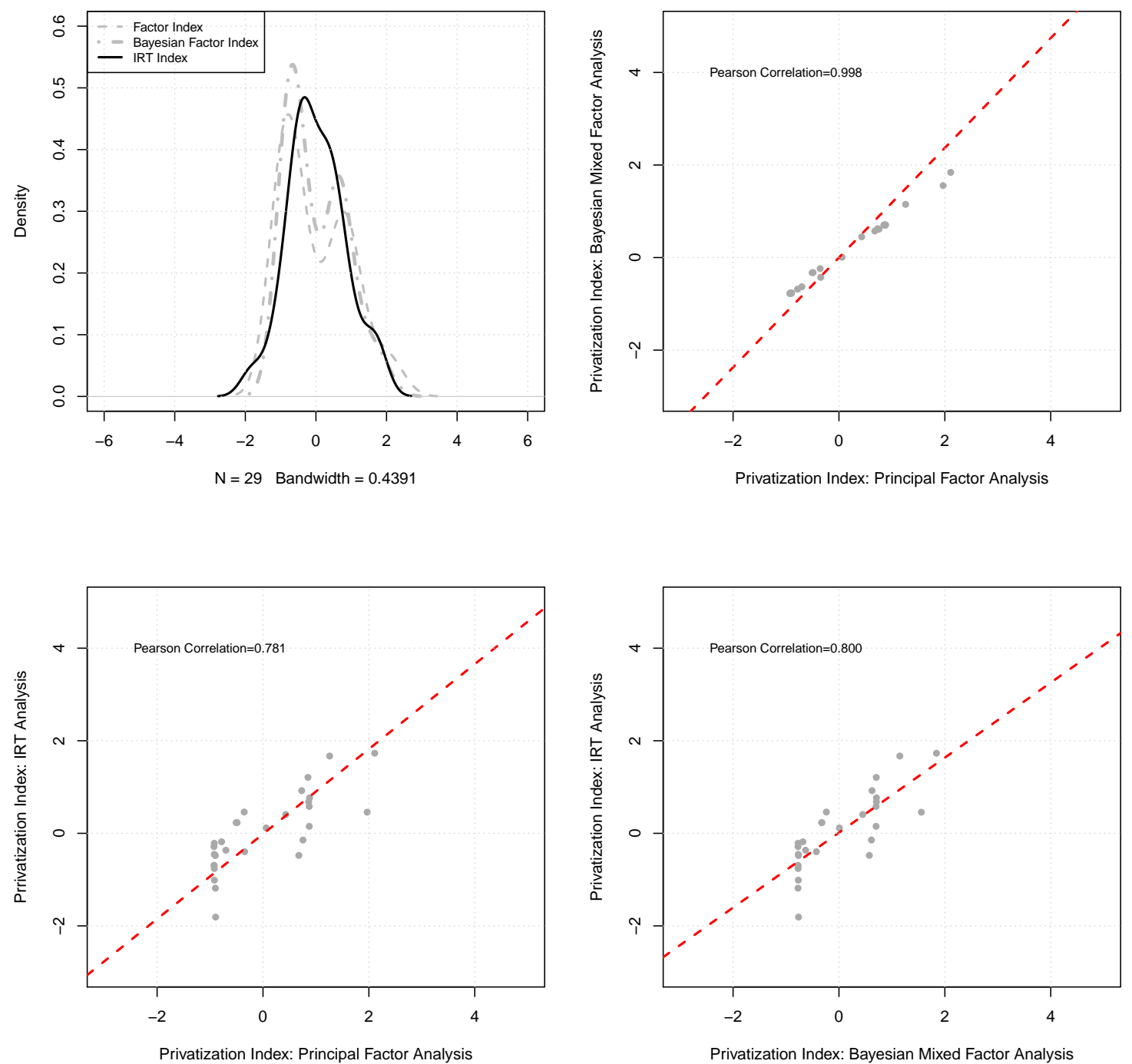

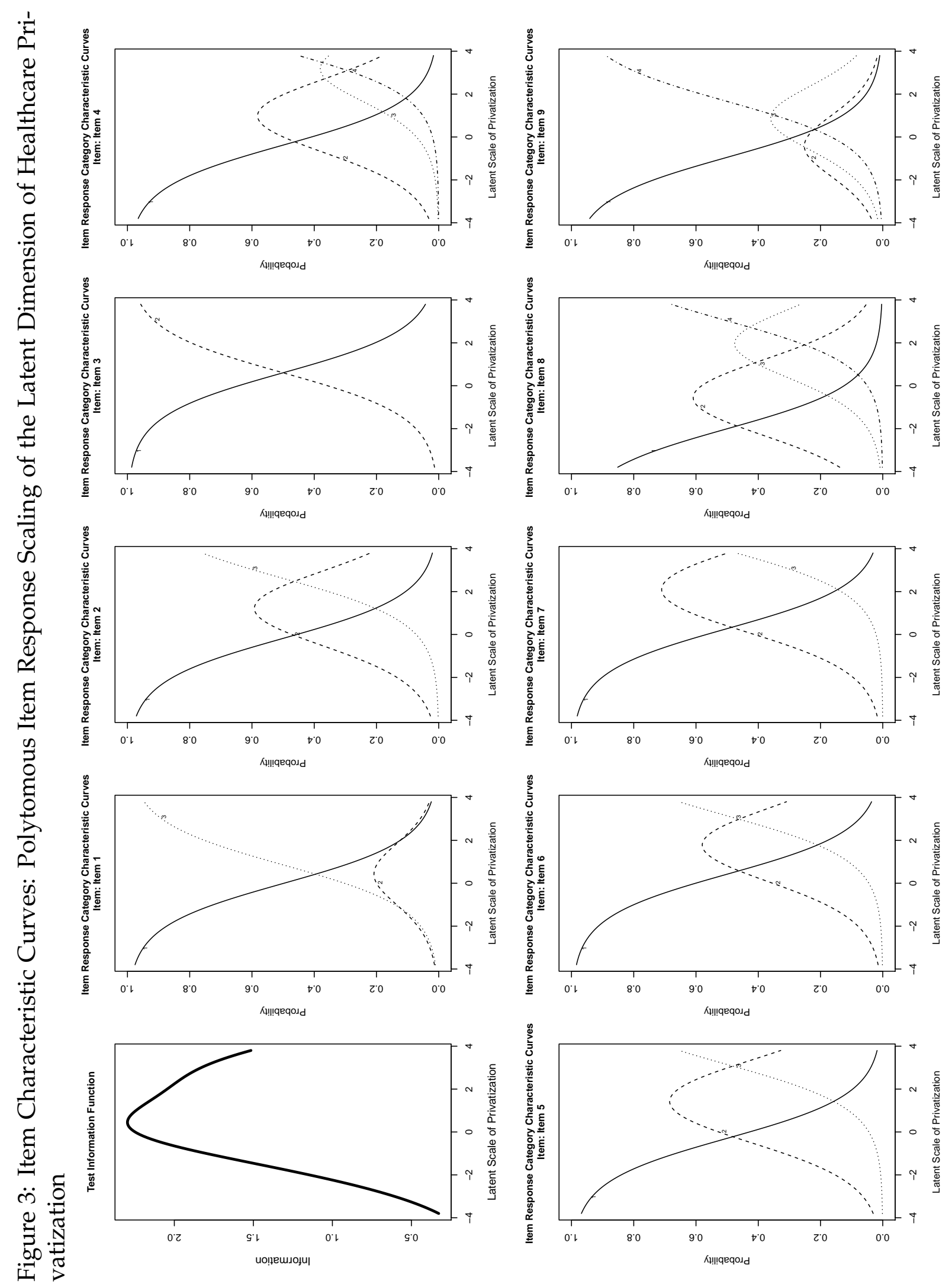


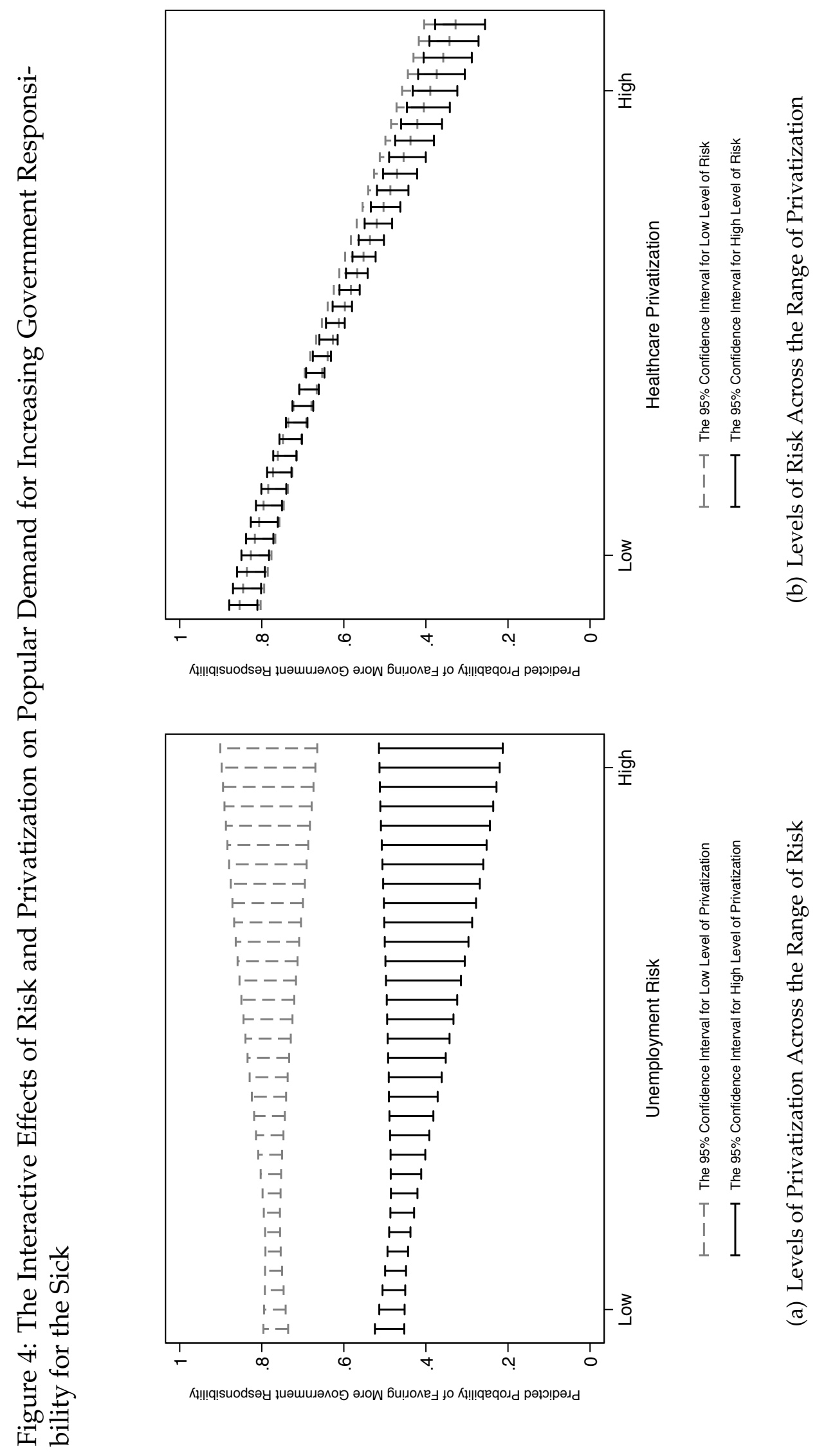




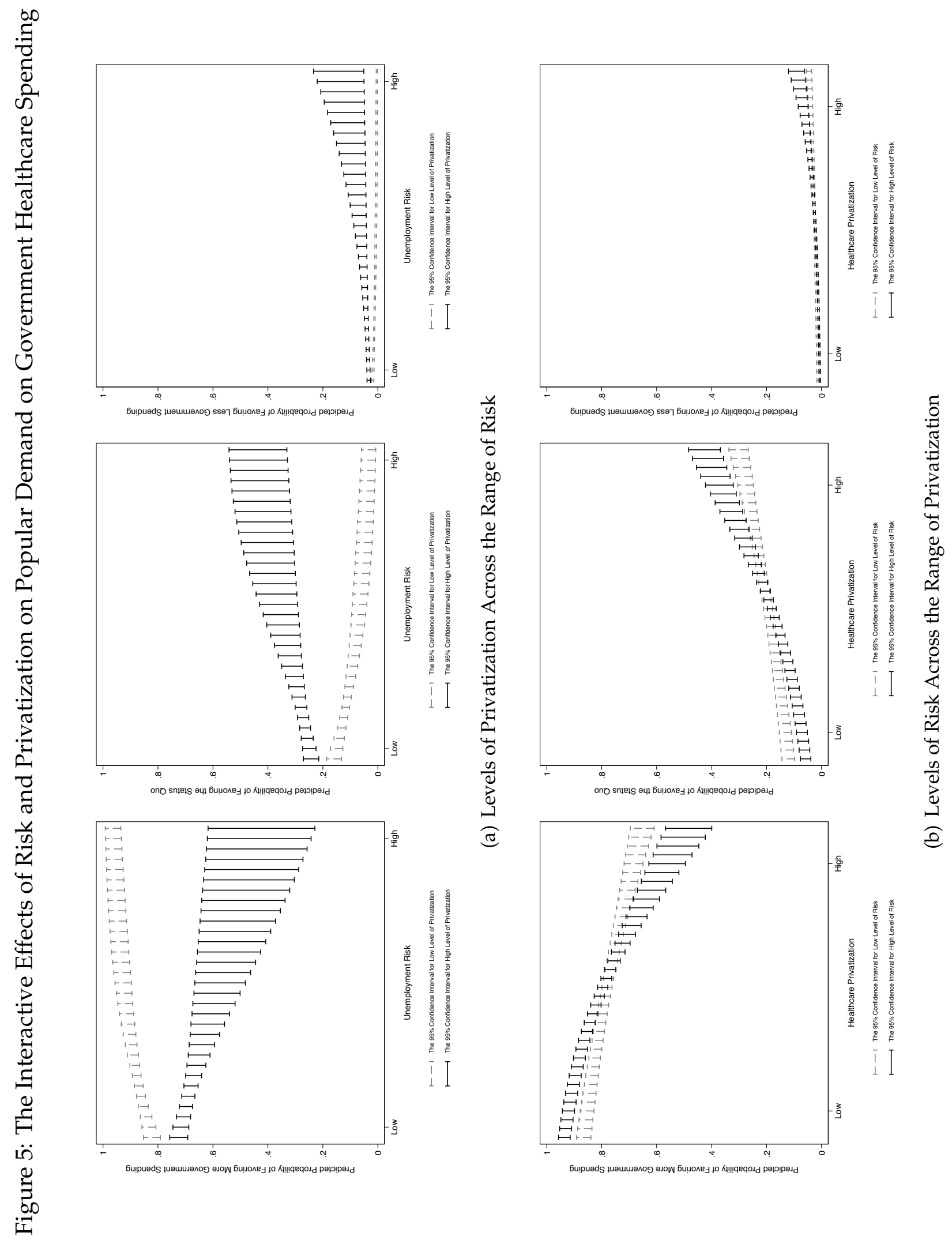


Figure 6: Bivariate Correlation between Aggregated Healthcare Preference and Privatization

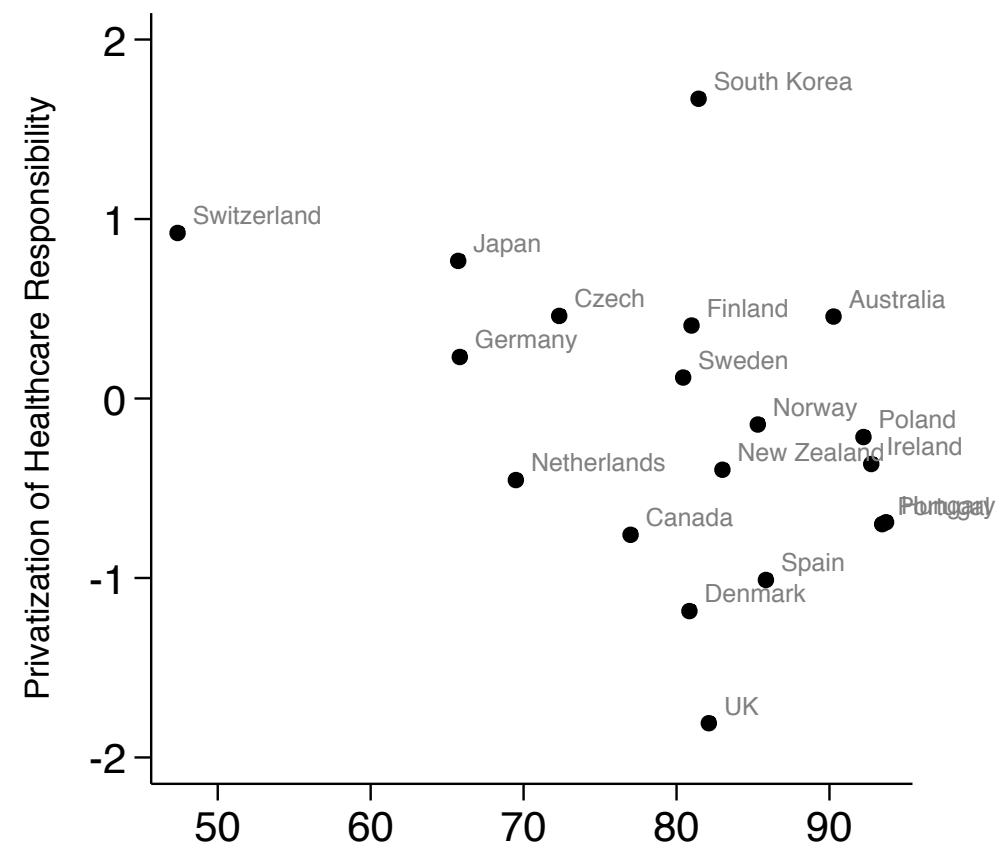

\% Respondents Supporting More Government Healthcare Spending 

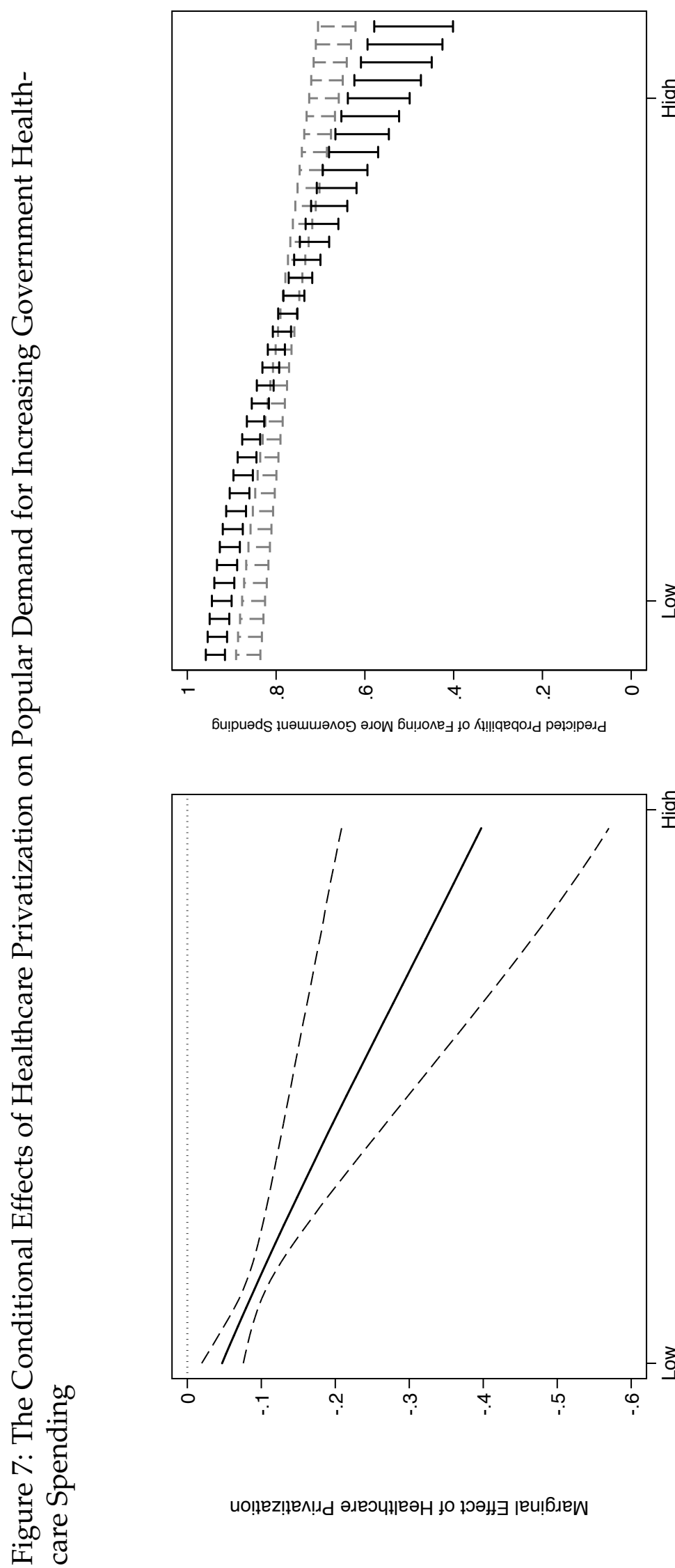

告
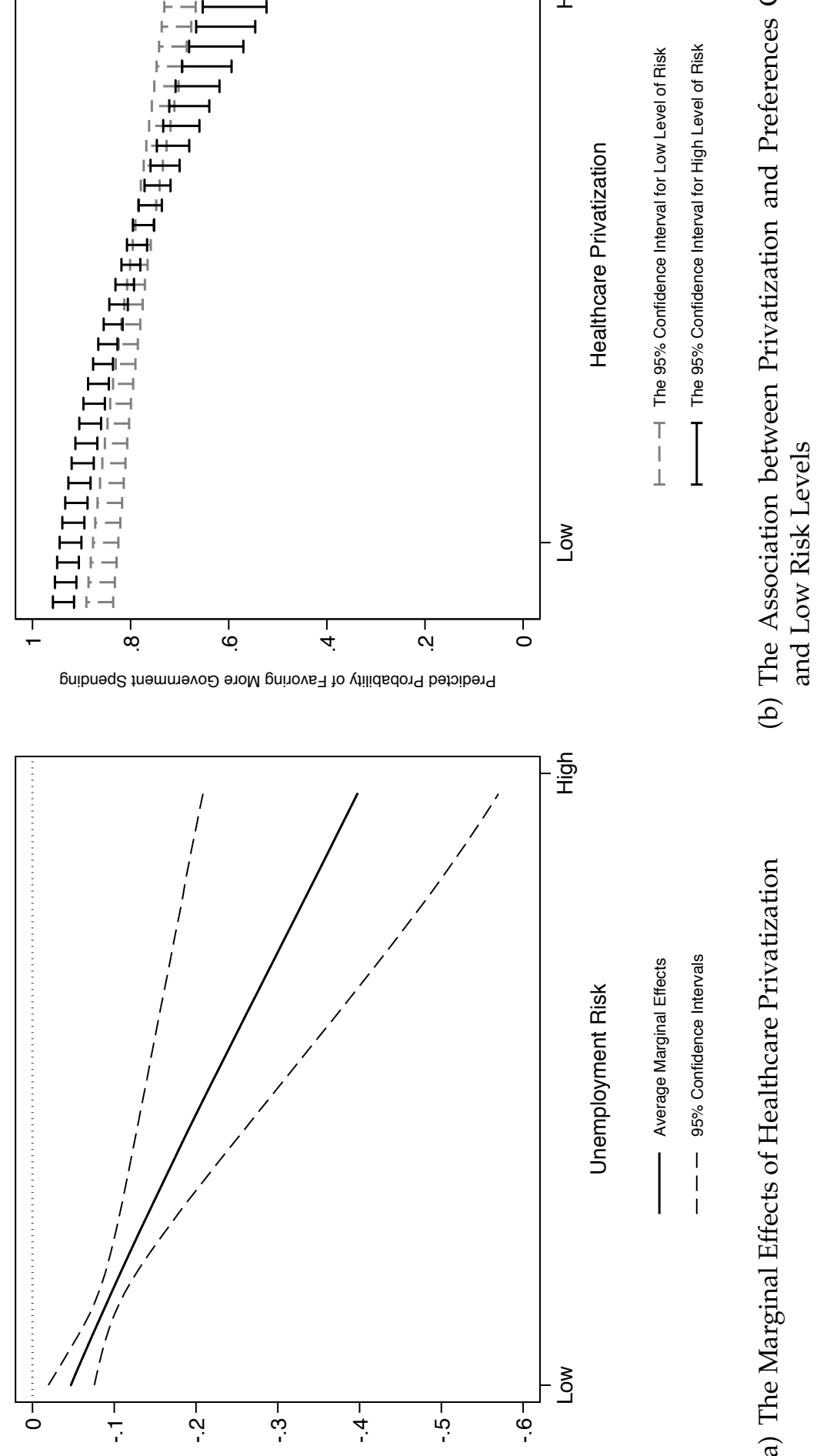

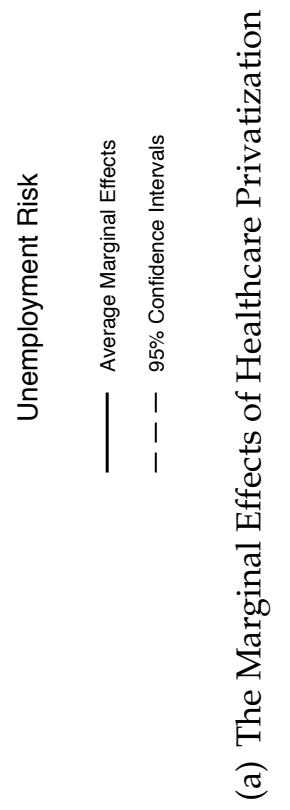

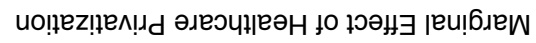

